University of Windsor

Scholarship at UWindsor

$1-2018$

\title{
Population-Specific Responses to Interspecific Competition in the Gut Microbiota of Two Atlantic Salmon (Salmo salar) Populations
}

\author{
Xiaoping $\mathrm{He}$ \\ University of Windsor \\ Subba Rao Chagantib \\ University of Windsor \\ Daniel D. Heath \\ University of Windsor
}

Follow this and additional works at: https://scholar.uwindsor.ca/glierpub

Part of the Biochemistry, Biophysics, and Structural Biology Commons, Biodiversity Commons, Biology Commons, and the Marine Biology Commons

\section{Recommended Citation}

He, Xiaoping; Chagantib, Subba Rao; and Heath, Daniel D.. (2018). Population-Specific Responses to Interspecific Competition in the Gut Microbiota of Two Atlantic Salmon (Salmo salar) Populations. Microbial Ecology, 75 (1), 140-151.

https://scholar.uwindsor.ca/glierpub/128

This Article is brought to you for free and open access by the Great Lakes Institute for Environmental Research at Scholarship at UWindsor. It has been accepted for inclusion in Great Lakes Institute for Environmental Research Publications by an authorized administrator of Scholarship at UWindsor. For more information, please contact scholarship@uwindsor.ca. 


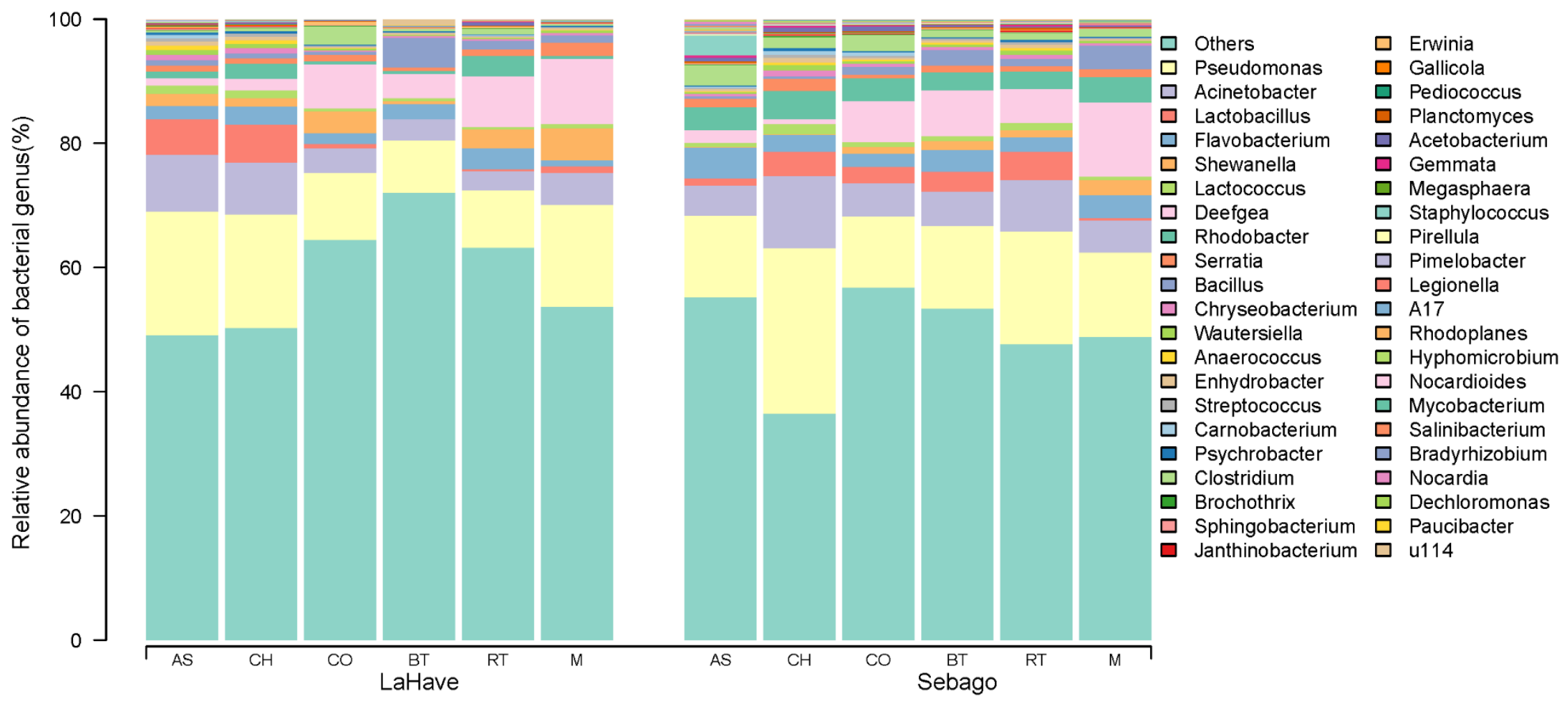

Figure 1 Relative abundance of bacterial genera for juvenile Atlantic salmon (Salmo salar) in response to interspecific competition. Displayed are genera with at least $0.1 \%$ relative abundance in one treatment. The "others" category includes unclassified sequences at the genus level and the sum of all genera that occurred at less than $0.1 \%$ relative abundance. Treatment symbols: AS indicates Atlantic salmon reared alone; $\mathrm{CH}, \mathrm{CO}, \mathrm{BT}$, and RT indicate Atlantic salmon reared with one of the four species: Chinook salmon, coho salmon, brown trout, and rainbow trout, respectively; M indicates Atlantic salmon reared with all four non-native salmonids. 

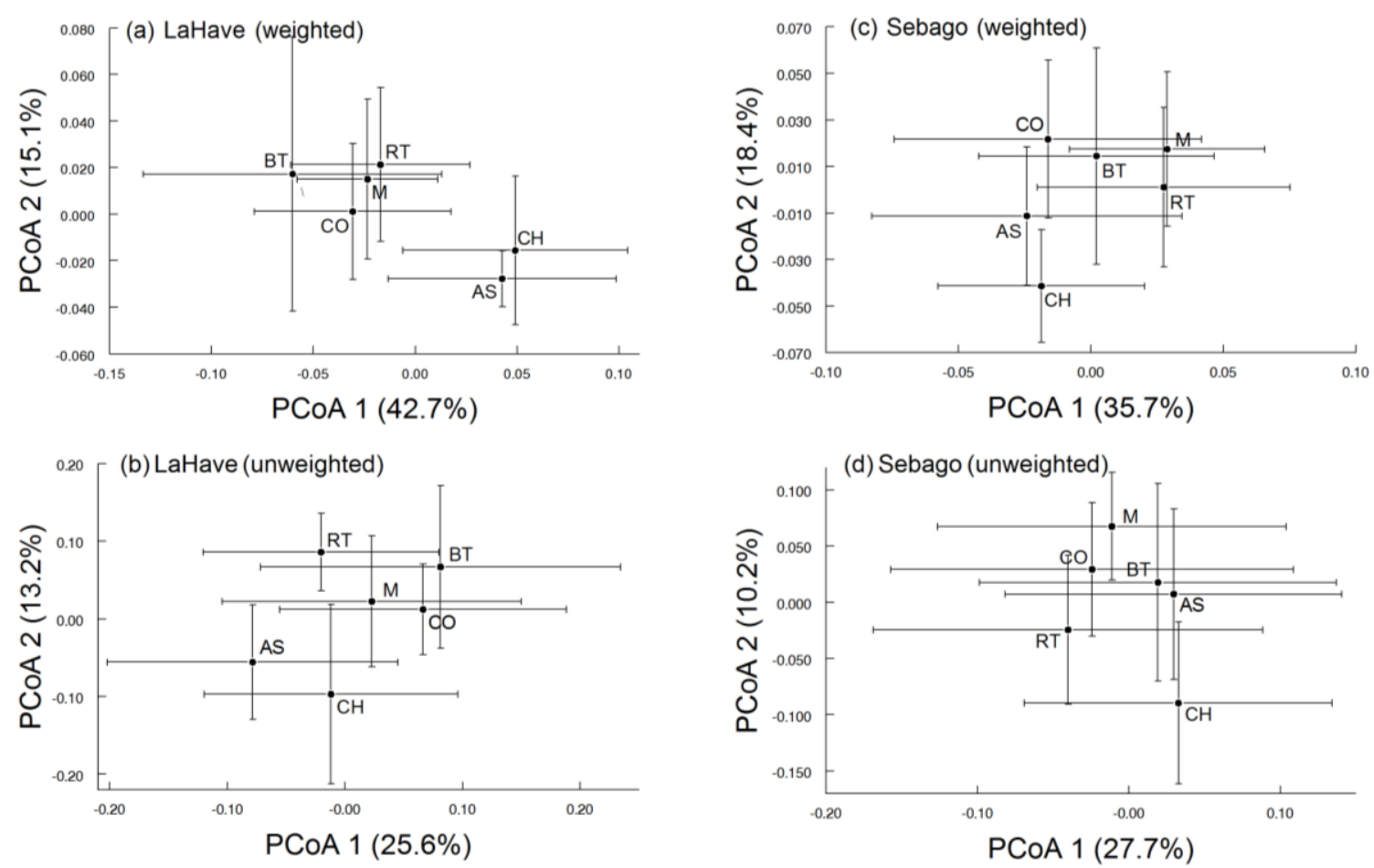

Figure 2 Principal coordinate analysis (PCoA) based on weighted and unweighted UniFrac distances for (a) the LaHave population with weighted UniFrac distances, (b) the LaHave population with unweighted UniFrac distances, (c) the Sebago population with weighted UniFrac distances and (d) the Sebago population with unweighted UniFrac distances. Each dot represents the average PCoA1 and PCoA2 values for one treatment and lines are the 95\% CIs. Treatment symbols: AS indicates Atlantic salmon reared alone; $\mathrm{CH}, \mathrm{CO}, \mathrm{BT}$ and RT indicate Atlantic salmon reared with one of the four species: Chinook salmon, coho salmon, brown trout and rainbow trout, respectively; $\mathrm{M}$ indicates Atlantic salmon reared with all four non-native salmonids. 


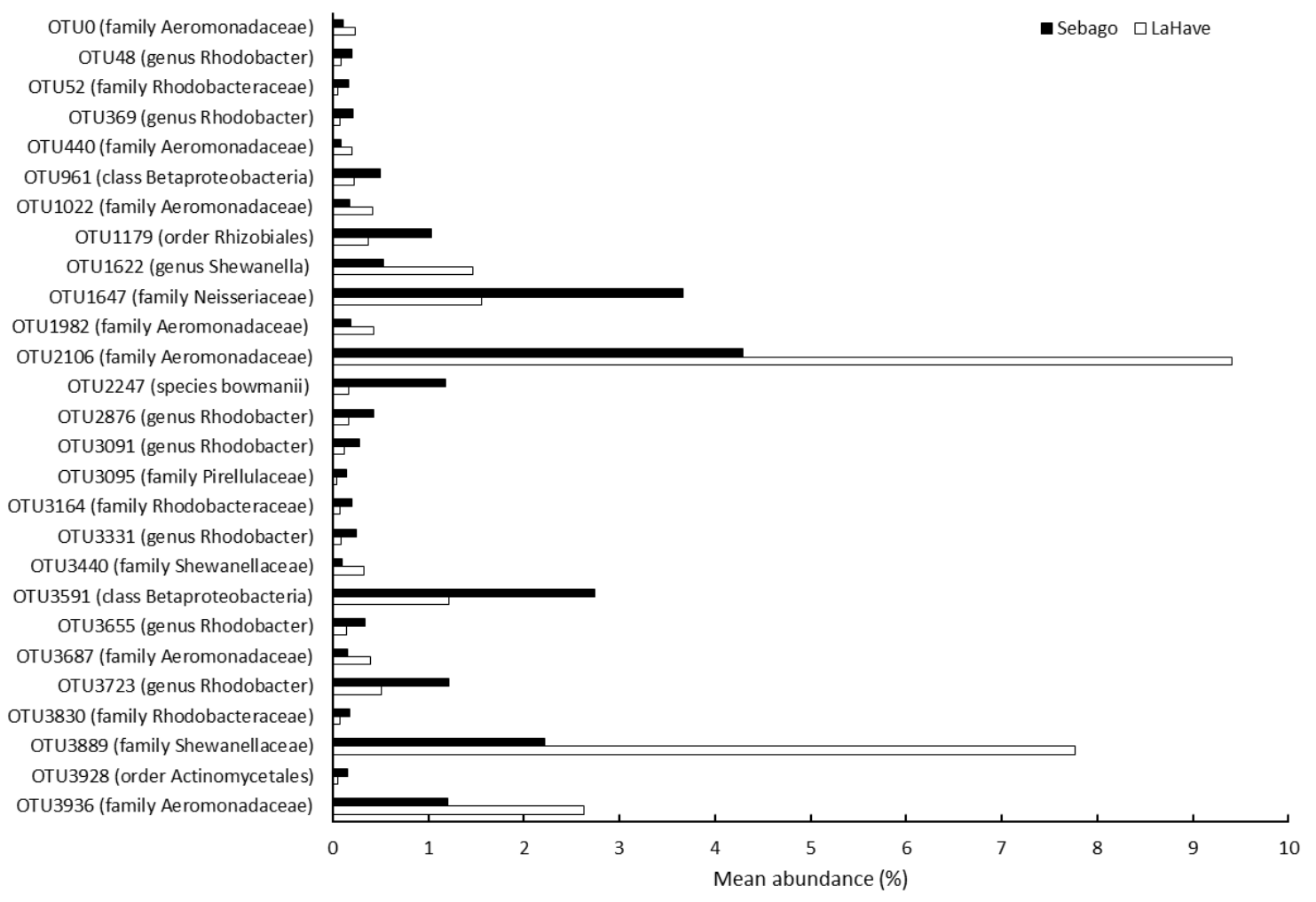

Figure 3 The 27 Operational Taxonomic Units (OTUs) that were significantly different in abundance between the two Atlantic salmon (Salmo salar) populations across all treatments. Taxonomic assignment beside each OTU identification number (see Table $\mathrm{S} 1)$ is the lowest taxonomic level obtained. 

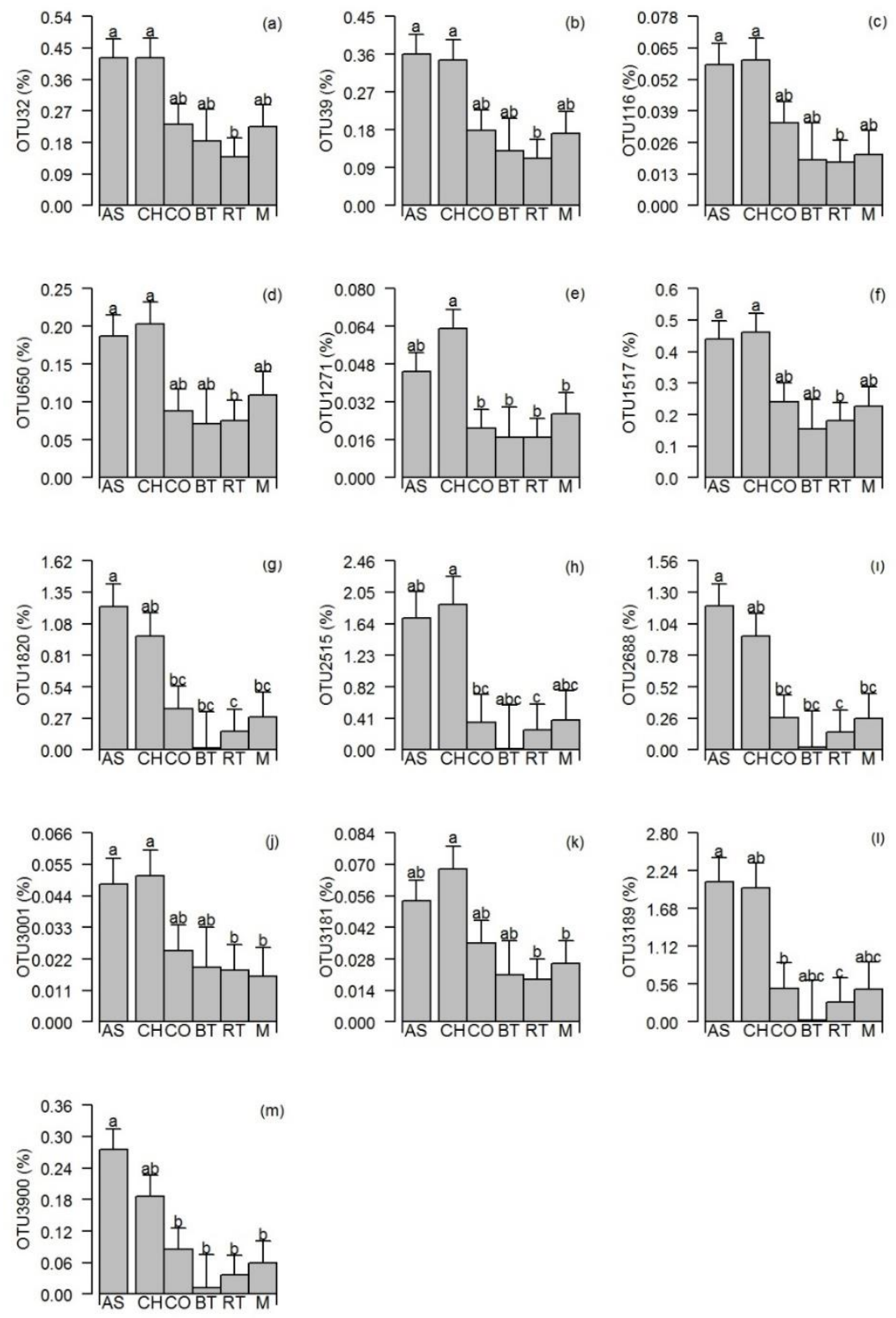

Figure 4 The 13 OTUs showing difference among competition treatments in the Atlantic salmon (Salmo salar) LaHave population: OTU32, 116, 650 and 1271 (genus Chryseobacterium), OTU39 (genus Flavobacterium), OTU1517 (species succinicans), OTU1820, 2515 and 3189 (genus Lactobacillus), OTU2688 (order Lactobacillales), OTU3001 (family Enterobacteriaceae), OTU3181 (genus Wautersiella), OTU3900 (genus Streptococcus). Displayed are means $\pm 1 \mathrm{SE}$ for treatments. Treatment symbols: AS indicates Atlantic salmon reared alone; $\mathrm{CH}, \mathrm{CO}, \mathrm{BT}$, and RT indicate Atlantic salmon reared with one of the four species: Chinook salmon, coho salmon, brown trout, and rainbow trout, respectively; $\mathrm{M}$ indicates Atlantic salmon reared with all four non-native salmonids. Different letters above the bars indicate significant differences assessed using Tukey's post hoc multiple comparisons $(P<0.05)$. 

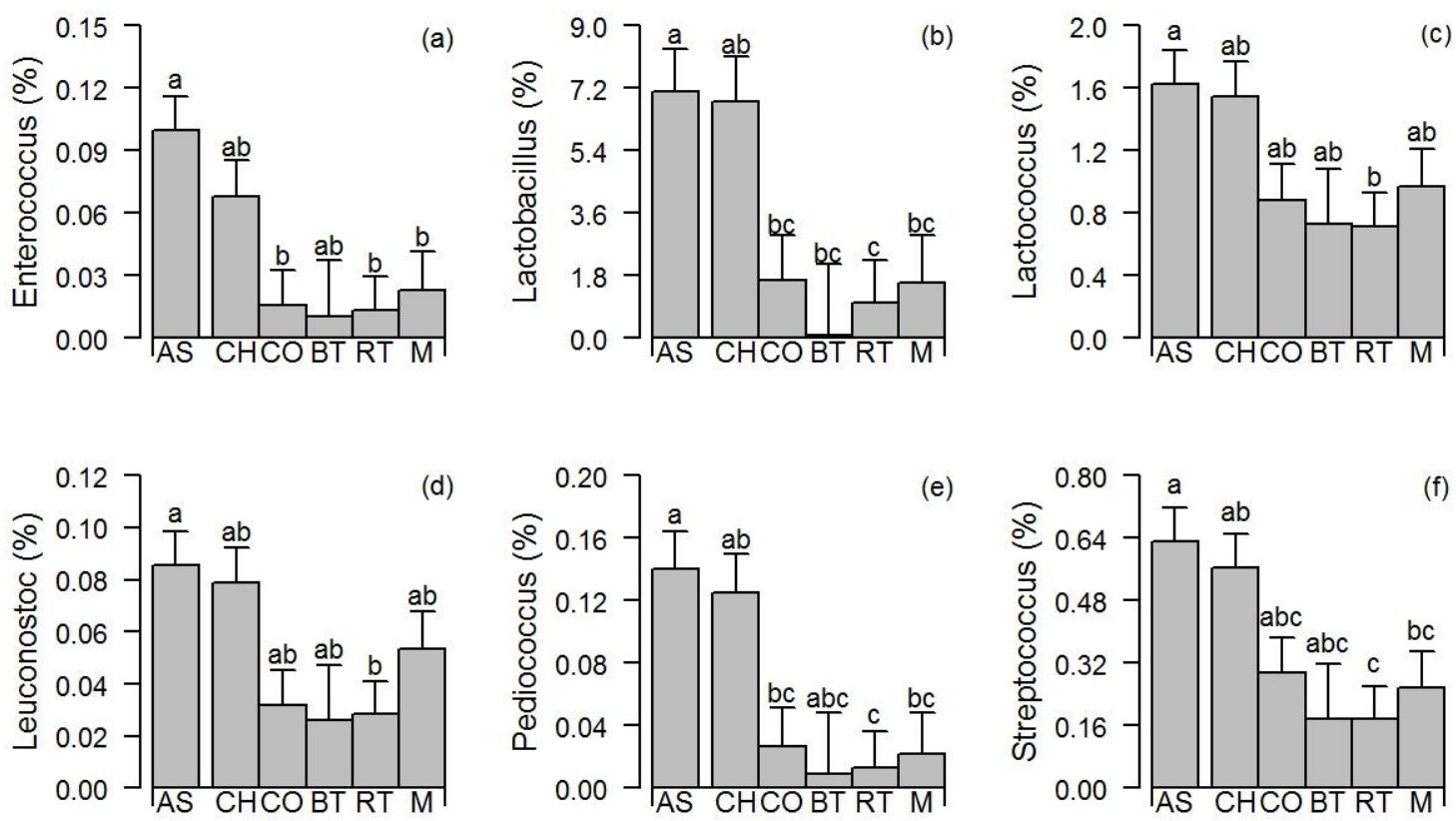

Figure 5 The six lactic acid genera showing differences among treatments in the Atlantic salmon (Salmo salar) LaHave population. Displayed are means \pm 1SE for treatments. Treatment symbols: AS indicates Atlantic salmon reared alone; $\mathrm{CH}, \mathrm{CO}, \mathrm{BT}$, and RT indicate Atlantic salmon reared with one of the four species: Chinook salmon, coho salmon, brown trout, and rainbow trout, respectively; $\mathrm{M}$ indicates Atlantic salmon reared with all four non-native salmonids. Different letters above the bars indicate significant differences assessed using Tukey's post hoc multiple comparisons $(P<0.05)$. 